\title{
Clinicopathologic Analysis of Sinonasal Inverted Papilloma, with Focus on Human Papillomavirus Infection Status
}

\author{
Munechika Tsumura ${ }^{1,2,+} \mathbb{D}$, Seiichiro Makihara ${ }^{1,2, *,+}{ }^{\mathbb{D}}$, Asami Nishikori ${ }^{3} \mathbb{D}$, Yuka Gion ${ }^{3,4} \mathbb{D}^{\mathbb{D}}$, Toshiaki Morito $^{5}$, \\ Shotaro Miyamoto ${ }^{1}$, Tomoyuki Naito ${ }^{6}$, Kensuke Uraguchi ${ }^{2} \mathbb{D}$, Aiko Oka ${ }^{7}$, Tomoyasu Tachibana ${ }^{8}$, Yorihisa Orita ${ }^{9}$, \\ Shin Kariya ${ }^{2}$, Mitsuhiro Okano ${ }^{7}$, Mizuo Ando ${ }^{2}$ and Yasuharu Sato ${ }^{3,10}{ }^{7}$
}

\section{check for} updates

Citation: Tsumura, M.; Makihara, S.; Nishikori, A.; Gion, Y.; Morito, T.; Miyamoto, S.; Naito, T.; Uraguchi, K.; Oka, A.; Tachibana, T.; et al. Clinicopathologic Analysis of Sinonasal Inverted Papilloma, with Focus on Human Papillomavirus Infection Status. Diagnostics 2022, 12, 454. https://doi.org/10.3390/ diagnostics12020454

Academic Editor: Ivana Kholová

Received: 26 January 2022

Accepted: 7 February 2022

Published: 10 February 2022

Publisher's Note: MDPI stays neutral with regard to jurisdictional claims in published maps and institutional affiliations.

Copyright: (C) 2022 by the authors. Licensee MDPI, Basel, Switzerland. This article is an open access article distributed under the terms and conditions of the Creative Commons Attribution (CC BY) license (https:// creativecommons.org/licenses/by/ $4.0 /)$.
1 Department of Otolaryngology Head and Neck Surgery, Kagawa Rosai Hospital, Marugame 763-8502, Japan; mwfcf214@yahoo.co.jp (M.T.); shotarrow@s.okayama-u.ac.jp (S.M.)

2 Department of Otolaryngology Head and Neck Surgery, Dentistry and Pharmaceutical Sciences, Graduate School of Medicine, Okayama University, Okayama 700-8558, Japan; pz6b2n7x@s.okayama-u.ac.jp (K.U.); skariya@cc.okayama-u.ac.jp (S.K.); ando-m@okayama-u.ac.jp (M.A.)

3 Division of Pathophysiology, Graduate School of Health Sciences, Okayama University, Okayama 700-8558, Japan; asami.kei@s.okayama-u.ac.jp (A.N.); ghe421017@gmail.com (Y.G.); satou-y@okayama-u.ac.jp (Y.S.)

4 Department of Medical Technology, Faculty of Health Sciences, Ehime Prefectural University of Health Sciences, Tobe 791-2101, Japan

5 Department of Pathology, Kagawa Rosai Hospital, Marugame 763-8502, Japan; morito_15j@yahoo.co.jp

6 Department of Otorhinolaryngology, Kagawa Prefectural Central Hospital, Takamatsu 760-8557, Japan; naitotomoyuki1@gmail.com

7 Department of Otorhinolaryngology, School of Medicine, International University of Health and Welfare, Narita 286-8520, Japan; aikooka@iuhw.ac.jp (A.O.); mokano@iuhw.ac.jp (M.O.)

8 Department of Otolaryngology, Japanese Red Cross Society Himeji Hospital, Himeji 670-8540, Japan; tomoyasutachibana@hotmail.co.jp

9 Department of Otolaryngology Head and Neck Surgery, Graduate School of Medicine, Kumamoto University, Kumamoto 860-8556, Japan; y.orita@live.jp

10 Department of Pathology, Dentistry and Pharmaceutical Sciences, Graduate School of Medicine, Okayama University, Okayama 700-8558, Japan

* Correspondence: seiichiromakiharajp@yahoo.co.jp; Tel./Fax: +81-877-23-3111

+ These authors contributed equally to this work.

\begin{abstract}
Sinonasal inverted papilloma (SNIP) can recur; however, the factors related to tumor recurrence remain unclear. This study aimed to analyze risk factors, including human papillomavirus (HPV) infection, as well as other factors associated with SNIP recurrence. Thirty-two patients who were diagnosed with SNIP and underwent surgery between 2010 and 2019 were enrolled: 24 men and 8 women, with a mean age of 59.2 years. The mean follow-up was 57.3 months. Demographics and information about history of smoking, diabetes mellitus (DM), hypertension, allergic rhinitis, alcohol consumption, tumor stage, surgical approach, and recurrence were reviewed retrospectively. Specimens were investigated using polymerase chain reaction to detect HPV DNA (high-risk subtypes: 16, $18,31,33,35,52 \mathrm{~b}$, and 58; low-risk subtypes: 6 and 11). Seven patients (21.9\%) experienced recurrence. HPV DNA was detected in five (15.6\%) patients (high-risk subtypes, $n=2$; low-risk subtypes, $n=3$ ). Patients with recurrence of SNIP had a higher proportion of young adults and displayed higher rates of HPV infection, DM, and advanced tumor stage than those without recurrence. HPV infection, young adulthood, DM, and advanced tumor stage could be associated with a high recurrence rate, which suggests that patients with these risk factors could require close follow-up after surgery.
\end{abstract}

Keywords: HPV infection; sinonasal inverted papilloma; diabetes mellitus; young adult; tumor stage

\section{Introduction}

Sinonasal inverted papilloma (SNIP) is a benign neoplasm of the nasal cavity and paranasal sinuses and accounts for $0.5-4 \%$ of primary nasal tumors [1]. SNIP has a tendency 
to recur (12-20\%), and malignant transformation has been found in 3-7\% of cases [2]. Thus, many ear, nose, and throat surgeons are interested in understanding which factors are related to tumor recurrence.

The etiology of SNIP remains unknown. Certain hypotheses have been proposed, but causality has never been established for the suspected factors of smoking, allergy, and human papillomavirus (HPV) infection [3]. Several staging systems have been indicated to provide a recurrence rate-driven prognosis [4].

For more than 30 years, HPV has been suspected to play a major role in the pathophysiology of SNIP. Several studies have reported higher HPV detection rates in recurrent SNIP cases [5-7], but there is contradictory information about whether HPV-associated SNIP has a higher risk of recurrence [8,9].

Therefore, this study aimed to analyze risk factors that are associated with the recurrence of SNIP, containing HPV infection, as well as other risk factors such as age, sex, medical history, smoking, alcohol consumption, tumor stage, and surgical approach.

\section{Materials and Methods}

\subsection{Patients}

The study population consisted of 32 patients with SNIP who were treated at Kagawa Rosai Hospital between 2010 and 2019. All patients were pathologically diagnosed with SNIP (Figure 1). The mean duration of follow-up for the patients after SNIP detection was 57.3 months (range, 24-120 months).
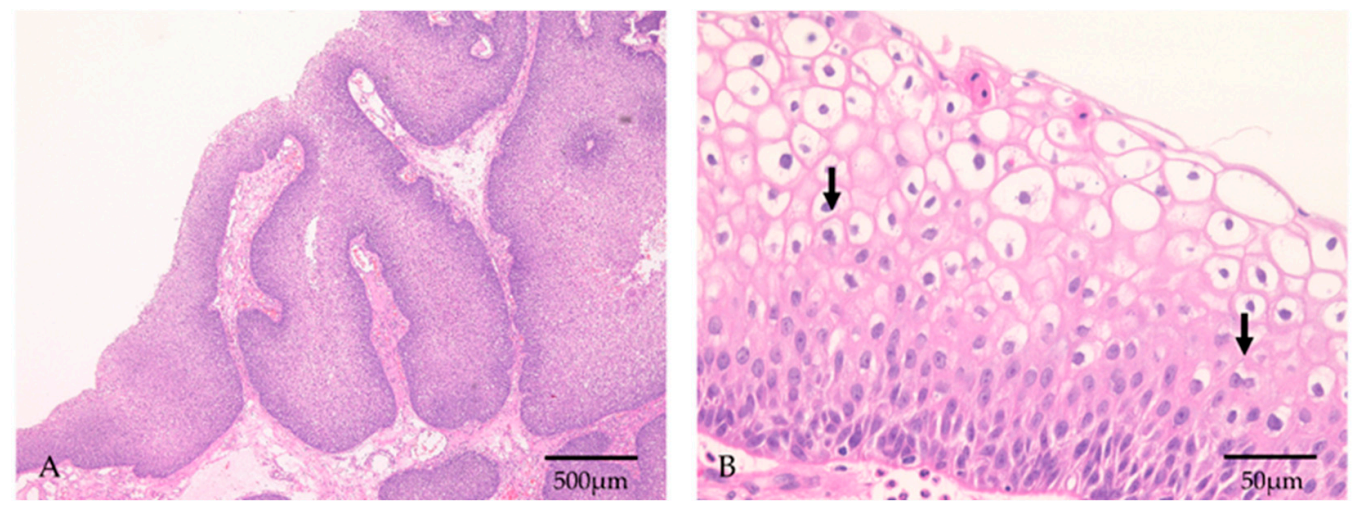

Figure 1. Histopathological features of HPV-positive SNIP. (A) The squamous epithelium showed an inverted growth pattern. Objective magnification: $4 \times$. (B) Koilocytosis was observed, which has a perinuclear halo. Some koilocytes showed nuclear atypia and binuclear cells (arrows). Objective magnification: $40 \times$.

We used opt-out to obtain consent for participation in this study.

Clinical characteristics were retrieved from patient medical records, which contained information on their medical history, including the presence of non-sinonasal papilloma, diabetes mellitus (DM), hypertension, and allergic rhinitis, as well as information on lifestyle characteristics (smoking and alcohol intake), occupational and industrial exposures such as welding fumes and organic solvents, primary symptoms, and complications after surgery. From the medical records, lifelong nonsmokers were defined as 'nonsmokers', and former smokers and current smokers as 'smokers'. We also defined lifelong nondrinkers and social drinkers as 'nondrinkers', and those who regularly drink several times per week as 'drinkers'.

All patients underwent preoperative computed tomography. The preoperative clinical stages of the initial surgeries were graded according to the Krouse staging system [10]. The tumor origin site was studied in relation to radiological features and intraoperative findings.

All surgeries were performed under general anesthesia using endoscopy, while external approaches, such as the Denker procedure or Caldwell-Luc operation, were added as needed for curative treatment. For complete surgical removal, accurate endoscopic 
identification and discrimination of the tumor from the surrounding normal mucosa were necessary. The tumor attachment site needed to be completely removed, and after it was removed, the part that was growing into the sinus was also extracted [11]. For the diagnosis of SNIP, histopathological examination was conducted for all patients. Patients with malignancies associated with tumors were excluded from this study. In each case, the specimen was analyzed and the following parameters were registered [12]: (i) enhanced hyperkeratosis or the presence of squamous hyperplasia, (ii) elevated mitotic index, (iii) lack of inflamed polyps, and (iv) greater number of aneuploid cells.

After surgical resection, the patients were followed up for at least two years to check for recurrence. Recurrence was defined as the presence of recurrent SNIP after initial curative treatment during the follow-up period. To rule out recurrent disease, patients were followed up after surgery, mainly by endoscopic examination.

\subsection{HPV DNA Testing}

HPV DNA was detected using consensus primer-mediated polymerase chain reaction (PCR) assays. Surgically removed tumor lesions were trimmed from formalinfixed paraffin-embedded (FFPE) blocks of inverted papillomas, followed by deparaffinization, and total DNA was extracted using the QIAamp DNA Micro Kit (Qiagen, Valencia, CA, USA). A section with a thickness of $3 \mu \mathrm{m}$ was prepared from the FFPE block, and the location of the lesion was confirmed by hematoxylin and eosin (HE) staining. Then, only the area with a high density of the tumor cells was dissected from the unstained slide, and DNA extraction was performed. PCR was performed using TaKaRa Taq ${ }^{\mathrm{TM}}$ (Takara Bio, Tokyo, Japan) and primers that detected HPV DNA, as reported previously [13-15]. The primers designed to target the E6 and E7 genes of HPV were a forward primer for low-risk HPV: 5'-TGCTAATTCGGTGCTACCTG-3'; a forward primer for high-risk HPV: 5'-TGTCAAAAACCGTTGTGTCC-3'; and reverse primer: 5'-GAGCTGTCGCTTAATTGCTC-3'. The reverse primer was fluorescently labeled, and the PCR product was analyzed using ABI PRISM 310 (Applied Biosystems, Foster City, CA, USA) and GeneMapper v3.7 (Applied Biosystems, Waltham, MA, USA). We defined a specimen as HPV-positive when a peak corresponding to a band size of 228 to $268 \mathrm{bp}$ was detected (Figure 2). Since the positive and negative controls for the HPV PCR assay have already been reported in the past, HPV PCR was determined based on them [15]. The seven HPV variants in Group 1 were considered as high-risk types (HPV 16, 18, 31, 33, 35, $52 \mathrm{~b}$, and 58), and the two HPV variants in Group 2 were considered as low-risk types (HPV 6 and 11) $[13,14]$.

A

A ${ }_{150}$

180

210

240

270
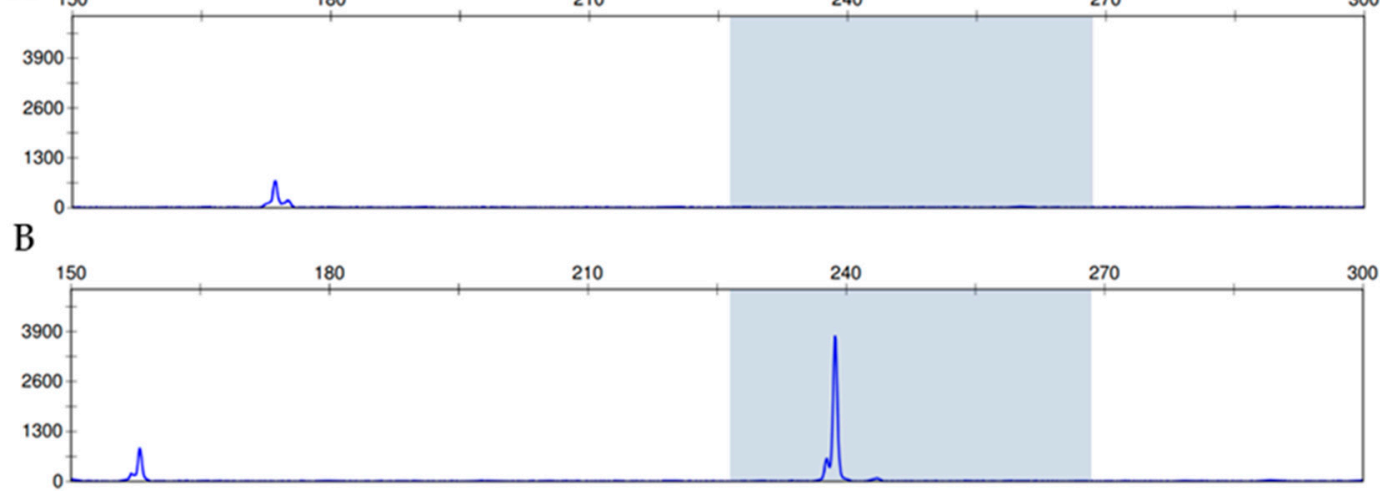

Figure 2. Criteria for fragment analysis. (A) Negative case, no peak at the expected fragment size of 228-268 bp (B) Positive case, a peak that is detected from the PCR product and represents a fragment size of 228-268 bp.

We also performed PCR on internal control genes to assess the validity of the HPV DNA amplification results. PCR was performed using the primers for $\beta$-actin and GAPDH $[16,17]$, and amplification products were confirmed by electrophoresis on a $3 \%$ agarose gel. 


\subsection{Statistical Analysis}

Differences in baseline characteristics were assessed using the chi-square test or Fisher's exact test, as appropriate. All statistical analyses were conducted using the statistical software 'EZR' (Easy R) [18]. Values with $p<0.05$ were accepted as significant, while those with $p<0.1$ were considered to indicate a tendency.

\section{Results}

\subsection{Overall Outcomes}

The 32 unoperated patients with SNIP included 24 men and 8 women, with a mean age of 59.2 years (range, 27-84 years) at the time of papilloma detection. In all cases, gross total resection was performed. Seven patients $(21.9 \%)$ experienced a recurrence. Nineteen $(59.4 \%)$ were smokers and $9(28.1 \%)$ drinkers. The number of patients with non-sinonasal papilloma, allergic rhinitis, DM, or hypertension was $0(0 \%), 10(31.3 \%), 5(15.6 \%)$, and $11(34.4 \%)$, respectively. There were no patients with occupational and industrial exposures, such as welding fumes or organic solvents. There were 27 patients with nasal obstruction, 4 with epistaxis, and 1 with postnasal drip. The number of tumor attachment sites varied between groups. There were 2 patients (6.3\%) with Krouse stage T1, 9 (28.1\%) with Krouse stage T2, 21 (65.6\%) with Krouse stage T3, and $0(0 \%)$ with Krouse stage T4. An endoscopic approach was performed in 29 patients, and combined approaches (both endoscopic and external approaches) in 3 patients. There were two patients with epistaxis and two with numbness of the cheek as complications. We could control epistaxis in both patients using bipolar cautery. The numbness of the cheek in two patients was resolved a few months after surgery. No major complications were observed. There were 15 patients $(46.9 \%)$ with enhanced hyperkeratosis or presence of squamous hyperplasia, $0(0 \%)$ with an elevated mitotic index, $0(0 \%)$ with a lack of inflamed polyps, and $0(0 \%)$ with a greater number of aneuploid cells. HPV DNA was detected in $5(15.6 \%)$ of the 32 patients with SNIP. Of these, two were positive for high-risk HPV subtypes, and three were positive for low-risk HPV subtypes.

\subsection{Association between Recurrence and Clinical Characteristics}

Younger adults ( $<40$ years) showed significant associations with recurrence compared to older adults ( $\geq 40$ years; $p=0.025$ ) (Table 1 ). Patients with DM showed significant associations with recurrence compared to those without DM $(p<0.01)$. Patients with Krouse stage T3 showed significant associations with recurrence compared to those with Krouse stages T1 or T2 $(p=0.030)$. Additionally, patients who had HPV high- or low-risk variants showed significant associations with recurrence, compared to those who were negative for HPV variants $(p=0.025)$.

Table 1. Association between Recurrence and Clinical Characteristics in Patients with Sinonasal Inverted Papilloma.

\begin{tabular}{lcccc}
\hline \multirow{2}{*}{ Sex } & & \multicolumn{3}{c}{ Recurrence } \\
\cline { 3 - 5 } & & $\mathbf{( + )}$ & $\mathbf{( - )}$ & $p$ Value \\
\hline \multirow{2}{*}{ Age } & Male & 6 & 18 & \\
& Female & 1 & 7 & 0.46 \\
\hline \multirow{2}{*}{ Smoker } & $\geq 40$ & 4 & 23 & \\
& $<40$ & 3 & 2 & 0.02 \\
\multirow{2}{*}{ Drinker } & Yes & 5 & 14 & \\
& No & 2 & 11 & 0.46 \\
\multirow{2}{*}{ History of allergic rhinitis } & Yes & 3 & 6 & \\
& No & 4 & 19 & 0.33 \\
\hline
\end{tabular}


Table 1. Cont.

\begin{tabular}{lcccc}
\hline & & \multicolumn{3}{c}{ Recurrence } \\
\cline { 3 - 5 } & & $\mathbf{( + )}$ & $\mathbf{( - )}$ & $p$ Value \\
\hline \multirow{2}{*}{ History of DM } & Yes & 4 & 1 & \\
& No & 3 & 24 & $<0.01$ \\
\hline \multirow{2}{*}{ History of hypertension } & Yes & 3 & 8 & \\
& No & 4 & 17 & 0.59 \\
\hline \multirow{2}{*}{ Staging } & T1 or T2 & 0 & 11 & \\
& T3 & 7 & 14 & 0.03 \\
\multirow{2}{*}{ Surgical methods } & Endoscopic excision & 6 & 23 & \\
& Endoscopic excision combined & 1 & 2 & 0.61 \\
EH or presence of SH & with external approach & & & \\
\hline \multirow{2}{*}{ HPV high or low risk (PCR) } & $(+)$ & 3 & 12 & \\
& $(-)$ & 4 & 13 & 0.81 \\
\hline
\end{tabular}

$\overline{\mathrm{DM}}=$ diabetes mellitus; $\mathrm{EH}$ = enhanced hyperkeratosis; $\mathrm{SH}=$ squamous hyperplasia. $(+)=$ recurrence + ; $(-)=$ recurrence - .

\subsection{Association between HPV Infection and Clinical Characteristics}

Younger patients ( $<40$ years) showed significantly stronger associations with HPV infection (positive for high- or low-risk HPV DNA) than older patients did ( $\geq 40$ years; $p<0.01$ ) (Table 2).

Table 2. Association Between HPV Infection and Clinical Characteristics in Patients with Sinonasal Inverted Papilloma.

\begin{tabular}{|c|c|c|c|c|}
\hline & & \multicolumn{3}{|c|}{ HPV High or Low Risk (PCR) } \\
\hline & & $(+)$ & $(-)$ & $p$ Value \\
\hline \multirow{2}{*}{ Sex } & Male & 5 & 19 & \\
\hline & Female & 0 & 8 & 0.16 \\
\hline \multirow{2}{*}{ Age } & $\geq 40$ & 2 & 25 & \\
\hline & $<40$ & 3 & 2 & $<0.01$ \\
\hline \multirow{2}{*}{ Smoker } & Yes & 4 & 15 & \\
\hline & No & 1 & 12 & 0.31 \\
\hline \multirow{2}{*}{ Drinker } & Yes & 1 & 8 & \\
\hline & No & 4 & 19 & 0.66 \\
\hline \multirow{2}{*}{ History of allergic rhinitis } & Yes & 2 & 8 & \\
\hline & No & 3 & 19 & 0.65 \\
\hline \multirow{2}{*}{ History of DM } & Yes & 2 & 3 & \\
\hline & No & 3 & 24 & 0.1 \\
\hline \multirow{2}{*}{ History of hypertension } & Yes & 2 & 9 & \\
\hline & No & 3 & 18 & 0.77 \\
\hline \multirow{2}{*}{ Staging } & $\mathrm{T} 1$ or $\mathrm{T} 2$ & 0 & 11 & \\
\hline & T3 & 5 & 16 & 0.08 \\
\hline \multirow[b]{2}{*}{ Surgical methods } & Endoscopic excision & 5 & 24 & \\
\hline & $\begin{array}{l}\text { Endoscopic excision combined } \\
\text { with external approach }\end{array}$ & 0 & 3 & 0.43 \\
\hline
\end{tabular}


Table 2. Cont.

\begin{tabular}{llccc}
\hline & & \multicolumn{3}{c}{ HPV High or Low Risk (PCR) } \\
\cline { 3 - 5 } & & $\mathbf{( + )}$ & $\mathbf{( - )}$ & $p$ Value \\
\hline \multirow{2}{*}{ EH or presence of SH } & $(+)$ & 3 & 12 & \\
& $(-)$ & 2 & 15 & 0.52 \\
\hline \multirow{2}{*}{ Recurrence } & Yes & 3 & 4 & \\
& No & 2 & 23 & 0.02 \\
\hline
\end{tabular}

DM, diabetes mellitus; EH, enhanced hyperkeratosis; SH, squamous hyperplasia. $(+)=$ detected $(-)=$ not detected.

\section{Discussion}

The results of our research on the relationship between clinical or demographic data and recurrence of SNIP showed that younger age ( $<40$ years), presence of DM, advanced tumor stage, and HPV DNA were associated with higher recurrence rates. Pähler et al. also reported that patients who presented with recurrent papilloma infection were significantly younger (48.7 years old on average) at the time of initial diagnosis than those (60.2 years old on average) with non-recurrent tumors $(p=0.0194)$, and multivariate logistic regression revealed that a younger age at initial diagnosis was the strongest risk factor for neoplasm recurrence [19]. In contrast, several reports found no relationship between recurrence and younger age $[4,20,21]$. Therefore, a detailed investigation with a large sample size is needed.

Patients with impaired immune responses have a greater tendency to develop HPVassociated disorders [22-24]. In patients with DM, a common chronic disease in Japan, the proliferation of macrophages and T cells is altered, and the function of $\mathrm{B}$ and NK cells is impaired, which results in abnormal innate and adaptive immunity [25]. Several biological mechanisms may possibly increase the incidence of HPV-related anogenital precancer and cancer occurrence in women with diabetes [26]. As one such mechanism, hyperglycemia in diabetes is related to cell-mediated immune deficiencies and an increased vulnerability to viral infections and, which may endanger clearance of HPV infections and thus boost progression to precancer and cancer development [26-28]. Moon et al. reported no relationship between recurrence and DM in 132 cases of SNIP [20]. The present study is the first to report the relationship between DM and SNIP recurrence, in addition to DM and HPV infections among patients with SNIP, partially because a limited number of studies examined SNIP and HPV infections.

Krouse [10], Han et al. [29], Cannady et al. [30], and others have proposed several classification staging systems for SNIP. The most widely used classification system is that of Krouse, which emphasizes that tumor extension over the medial maxillary sinus or to the frontal or sphenoid sinus is an important prognostic factor [20,31]. Of the recurrences reported by Gras-Cabrerizo et al. [31] according to the Krouse system: 0\% occurred in the T1 stage, $16 \%$ in the T2 stage, $25 \%$ in the T3 stage, and $60 \%$ in the T4 stage ( $p=0.05$ ). Furthermore, Moon et al. reported that the Krouse stage T4 group had more frequent recurrences than the T1, T2, and T3 groups did [20]. This study found that patients with Krouse stage T3 showed significant associations with recurrence, compared to those with $\mathrm{T} 1$ or $\mathrm{T} 2$.

$\mathrm{HPV}$, an epitheliotropic DNA virus, can infect the epidermis or mucosa in humans. During infection, viral DNA sequences of HPV are incorporated into cellular DNA and play a key role in the promotion of neoplasm growth and malignant transformation of SNIP [32]. The detection method and detection rate of HPV-PCR are important points, and there have been several studies that employ HPV-PCR in FFPE samples [33-35]. The internal control gene amplification was performed to assess the validity of the results obtained in this study. $\beta$-actin and GAPDH were used as the internal controls [16,17]. $\beta$-actin $(258 \mathrm{bp})$ was amplified in 31 of 32 cases, and GAPDH (226 bp) was amplified in all cases (Figure S1). These results suggest that HPV-PCR approach is unlikely to result in false negatives due 
to DNA fragmentation because of formalin fixation. Consistent with detections from previous reports, those with malignant and benign clinical courses could be separated based on high- and low-risk types of HPV, respectively. HPV-6 and -11 are considered as low-grade risk types, while HPV-16 and -18 are considered as high-grade risk types [36]. The detection rate of HPV was increased in SNIP with carcinoma and high-grade dysplasia, as compared to that in SNIP with mild dysplasia or no dysplasia [37]. Meta-analyses showed a significant relationship between HPV infection and malignant transformation of SNIP [38,39]. Additionally, several studies reported that patients who were SNIP positive for HPV infection showed higher levels of recurrence than those who were SNIP-negative for HPV infection [5-7]. In contrast, a study of 57 patients reported HPV DNA in seven SNIP areas, all of which were grades II and I (benign) SNIP cases. All other cases were grade III or grade IV (carcinoma arising from SNIP) and negative for HPV DNA. High-risk HPV subtype DNA was found in five of seven cases, suggesting that infection, especially with high-risk HPV subtypes, was an early and stimulating event in tumorigenesis [40]. Taken together, these studies suggest that HPV plays a key role in not only malignant transformation, but also early pathological development and recurrence [36].

Smoking is considered the most momentous risk factor for the development and recurrence of tumors occurring in the head, neck, and uterine cervix regions [36,41]. As one of the environmental risk factors, smoking has been associated with recurrence of SNIP. In a study of 132 patients, SNIP had recurrence in 21 of 132 (15.9\%) patients. While 11 of the 39 smokers $(28.2 \%)$ had recurrence of the disease, only 10 of the 93 nonsmokers $(10.7 \%)$ had recurrence, which showed a significantly higher rate of recurrence among smokers $(p=0.012)$ [20]. This study found no significant difference between nonsmokers and smokers in the incidence of SNIP recurrence.

A systematic review and meta-analysis indicated that an endoscopic approach was an approving treatment option for SNIP and confirmed a global recommendation that it is the world standard in the treatment of such nose lesions, discovering a lower recurrence rate than that in external approaches. However, the recurrence rate did not show a significant difference between the endoscopic and combined approach groups [42]. Even when an external approach is necessary, the combination of an endoscopic approach is important for suppressing recurrence, as was observed in this study.

Despite being performed in a single institution, this study had limitations. First, the low positivity rate of HPV DNA made it difficult to evaluate the influence of HPV infection on the SNIP recurrence. Only 5 of 32 patients (15.6\%) were positive for HPV DNA in the present study. Three recent PCR-based studies detected HPV in 11 of 90 patients $(12.2 \%)$ [37], 2 of 19 patients (10.5\%) [43], and 8 of 54 patients $(14.8 \%)$ [4]. The low prevalence of HPV reflects the possibility that HPV infection is not the main causal factor for the pathogenesis of SNIP. Second, there were few patients with the T1 stage according to the Krouse system, and no patient with T4 stage. Furthermore, the number of young patients recruited in this study was small. A multicenter study with a large sample size is needed to establish the relationship between SNIP recurrence and HPV infection and identify additional risk factors associated with recurrence.

\section{Conclusions}

This study examined the risk factors for SNIP recurrence after surgical resection. HPV infection, young adulthood, DM, and advanced tumor stage were associated with a high recurrence rate. These results suggest that patients with these risk factors require information about risk factors and close follow-up after surgery. In the future, a multicenter study with a large sample size will be conducted to establish the relationship between SNIP recurrence and HPV infection, and the relationship between recurrence and other risk factors. 
Supplementary Materials: The following supporting information can be downloaded at: https: / / www.mdpi.com/article/10.3390/diagnostics12020454/s1, Figure S1. The internal control gene amplification. $\beta$-actin ( $258 \mathrm{bp}$ ) was amplified in 31 of 32 cases, and GAPDH (226 bp) was amplified in all cases. NC, negative control.

Author Contributions: Conceptualization, S.M. (Seiichiro Makihara) and Y.S.; methodology, S.M. (Seiichiro Makihara), T.T., Y.O. and Y.S.; validation, S.K., M.O. and M.A.; formal analysis, S.M. (Seiichiro Makihara); investigation, S.M. (Seiichiro Makihara), T.M., S.M. (Shotaro Miyamoto), T.N., K.U. and A.O.; data curation, S.M. (Seiichiro Makihara) and T.M.; writing-original draft preparation, M.T., S.M. (Seiichiro Makihara), A.N. and Y.G.; writing-review and editing, M.T. and S.M. (Seiichiro Makihara); supervision, Y.S.; project administration, S.M. (Seiichiro Makihara). All authors have read and agreed to the published version of the manuscript.

Funding: This research received no external funding.

Institutional Review Board Statement: The study was conducted according to the guidelines of the Declaration of Helsinki, and approved by the Institutional Review Board (or Ethics Committee) of Kagawa Rosai Hospital (protocol code R1-10 and date of approval (7 June 2019)).

Informed Consent Statement: Informed consent was obtained from all subjects involved in the study. Data Availability Statement: Not applicable.

Conflicts of Interest: The authors declare no conflict of interest.

\section{References}

1. Mirza, S.; Bradley, P.J.; Acharya, A.; Stacey, M.; Jones, N.S. Sinonasal inverted papillomas: Recurrence, and synchronous and metachronous malignancy. J. Laryngol. Otol. 2007, 121, 857-864. [CrossRef] [PubMed]

2. Adriaensen, G.F.; Lim, K.H.; Georgalas, C.; Reinartz, S.M.; Fokkens, W.J. Challenges in the Management of Inverted Papilloma: A Review of 72 Revision Cases. Laryngoscope 2016, 126, 322-328. [CrossRef]

3. Lisan, Q.; Laccourreye, O.; Bonfils, P. Sinonasal inverted papilloma: From diagnosis to treatment. Eur. Ann. Otorhinolaryngol. Head Neck Dis. 2016, 133, 337-341. [CrossRef]

4. Roh, H.J.; Mun, S.J.; Cho, K.S.; Hong, S.L. Smoking, not human papilloma virus infection, is a risk factor for recurrence of sinonasal inverted papilloma. Am. J. Rhinol. Allergy 2016, 30, 79-82. [CrossRef] [PubMed]

5. Hwang, C.S.; Yang, H.S.; Hong, M.K. Detection of human papillomavirus (HPV) in sinonasal inverted papillomas using polymerase chain reaction (PCR). Am. J. Rhinol. 1998, 12, 363-366. [CrossRef]

6. $\quad$ Beck, J.C.; McClatchey, K.D.; Lesperance, M.M.; Esclamado, R.M.; Carey, T.E.; Bradford, C.R. Human papillomavirus types important in progression of inverted papilloma. Otolaryngol. Head Neck Surg. 1995, 113, 558-563. [CrossRef]

7. Beck, J.C.; McClatchey, K.D.; Lesperance, M.M.; Esclamado, R.M.; Carey, T.E.; Bradford, C.R. Presence of human papillomavirus predicts recurrence of inverted papilloma. Otolaryngol. Head Neck Surg. 1995, 113, 49-55. [CrossRef]

8. Kraft, M.; Simmen, D.; Casas, R.; Pfaltz, M. Significance of human papillomavirus in sinonasal papillomas. J. Laryngol. Otol. 2001, 115, 709-714. [CrossRef] [PubMed]

9. Jenko, K.; Kocjan, B.; Zidar, N.; Poljak, M.; Strojan, P.; Zargi, M.; Blatnik, O.; Gale, N. In inverted papillomas HPV more likely represents incidental colonization than an etiological factor. Virchows Arch. 2011, 459, 529-538. [CrossRef] [PubMed]

10. Krouse, J.H. Development of a staging system for inverted papilloma. Laryngoscope 2000, 110, 965-968. [CrossRef]

11. Makihara, S.; Kariya, S.; Naito, T.; Uraguchi, K.; Matsumoto, J.; Noda, Y.; Okano, M.; Nishizaki, K. Attachment-oriented endoscopic surgical management for inverted papillomas in the nasal cavity and paranasal sinuses. Auris Nasus Larynx 2019, 46, 748-753. [CrossRef] [PubMed]

12. Katori, H.; Nozawa, A.; Tsukuda, M. Histopathological parameters of recurrence and malignant transformation in sinonasal inverted papilloma. Acta Otolaryngol. 2006, 126, 214-218. [CrossRef] [PubMed]

13. Tachibana, T.; Orita, Y.; Gion, Y.; Miki, K.; Ikegami, K.; Marunaka, H.; Makino, T.; Akagi, Y.; Akisada, N.; Tsumura, M.; et al. Young adult patients with squamous cell carcinoma of the tongue strongly express p16 without human papillomavirus infection. Acta Otolaryngol. 2019, 139, 80-84. [CrossRef] [PubMed]

14. Orita, Y.; Gion, Y.; Tachibana, T.; Ikegami, K.; Marunaka, H.; Makihara, S.; Yamashita, Y.; Miki, K.; Makino, T.; Akisada, N.; et al. Laryngeal squamous cell papilloma is highly associated with human papillomavirus. Jap. J. Clin. Oncol. 2018, 48, 350-355. [CrossRef]

15. Saiki, Y.; Gion, Y.; Nishikori, A.; Norimatsu, Y.; Sato, Y. Comparison of the Hybrid Capture II Method with a PCR-Based Screening Method Using a Carboxyfluorescein-Labeled Primer for Detecting Human Papillomavirus in Cervicovaginal Liquid-Based Cytology. J. Mol. Pathol. 2020, 1, 9-18. [CrossRef]

16. Sengüven, B.; Baris, E.; Oygur, T.; Berktas, M. Comparison of methods for the extraction of DNA from formalin-fixed, paraffinembedded archival tissues. Int. J. Med. Sci. 2014, 11, 494-499. [CrossRef] 
17. Panchal, N.K.; Bhale, A.; Chowdary, R.; Verma, V.K.; Beevi, S.S. PCR Amplifiable DNA from Breast Disease FFPE Section for Mutational Analysis. J. Biomol. Tech. 2020, 31, 1-6. [CrossRef]

18. Kanda, Y. Investigation of the freely available easy-to-use software 'EZR' for medical statistics. Bone Marrow Transp. 2013, 48, 452-458. [CrossRef]

19. Pähler Vor der Holte, A.; Fangk, I.; Glombitza, S.; Wilkens, L.; Welkoborsky, H.J. Prognostic factors and risk factors for development and recurrence of sinonasal papillomas: Potential role of different HPV subtypes. Eur. Arch. Otorhinolaryngol. 2020, 277, 767-775. [CrossRef]

20. Moon, I.J.; Lee, D.Y.; Suh, M.W.; Han, D.H.; Kim, S.T.; Min, Y.G.; Lee, C.H.; Rhee, C.S. Cigarette smoking increases risk of recurrence for sinonasal inverted papilloma. Am. J. Rhinol. Allergy 2010, 24, 325-329. [CrossRef]

21. Lisan, Q.; Laccourreye, O.; Bonfils, P. Sinonasal Inverted Papilloma: Risk Factors for Local Recurrence After Surgical Resection. Ann. Otol. Rhinol. Laryngol. 2017, 126, 498-504. [CrossRef] [PubMed]

22. Geerlings, S.E.; Hoepelman, A.I. Immune dysfunction in patients with diabetes mellitus (DM). FEMS Immunol. Med. Microbiol. 1999, 26, 259-265. [CrossRef] [PubMed]

23. Heard, I.; Palefsky, J.M.; Kazatchkine, M.D. The impact of HIV antiviral therapy on human papillomavirus (HPV) infections and HPV-related diseases. Antivir. Ther. 2004, 9, 13-22. [PubMed]

24. Yong, M.; Parkinson, K.; Goenka, N.; O'Mahony, C. Diabetes and genital warts: An unhappy coalition. Int. J. STD AIDS 2010, 21, 457-459. [CrossRef]

25. Zhou, T.; Hu, Z.; Yang, S.; Sun, L.; Yu, Z.; Wang, G. Role of Adaptive and Innate Immunity in Type 2 Diabetes Mellitus. J. Diabetes Res. 2018, 2018, 7457269. [CrossRef]

26. Reinholdt, K.; Thomsen, L.T.; Munk, C.; Dehlendorff, C.; Aalborg, G.L.; Carstensen, B.; Jørgensen, M.E.; Kjaer, S.K. Incidence of human papillomavirus-related anogenital precancer and cancer in women with diabetes: A nationwide registry-based cohort study. Int. J. Cancer 2021, 148, 2090-2101. [CrossRef]

27. Mor, A.; Dekkers, O.M.; Nielsen, J.S.; Beck-Nielsen, H.; Sørensen, H.T.; Thomsen, R.W. Impact of Glycemic Control on Risk of Infections in Patients with Type 2 Diabetes: A Population-Based Cohort Study. Am. J. Epidemiol. 2017, 186, 227-236. [CrossRef] [PubMed]

28. Abu-Ashour, W.; Twells, L.; Valcour, J.; Randell, A.; Donnan, J.; Howse, P.; Gamble, J.M. The association between diabetes mellitus and incident infections: A systematic review and meta-analysis of observational studies. BMJ Open Diabetes Res. Care 2017, 5, e000336. [CrossRef]

29. Han, J.K.; Smith, T.L.; Loehrl, T.; Toohill, R.J.; Smith, M.M. An evolution in the management of sinonasal inverting papilloma. Laryngoscope 2001, 111, 1395-1400. [CrossRef]

30. Cannady, S.B.; Batra, P.S.; Sautter, N.B.; Roh, H.J.; Citardi, M.J. New staging system for sinonasal inverted papilloma in the endoscopic era. Laryngoscope 2007, 117, 1283-1287. [CrossRef] [PubMed]

31. Gras-Cabrerizo, J.R.; Montserrat-Gili, J.R.; Massegur-Solench, H.; León-Vintró, X.; De Juan, J.; Fabra-Llopis, J.M. Management of sinonasal inverted papillomas and comparison of classification staging systems. Am. J. Rhinol. Allergy 2010, 24, 66-69. [CrossRef] [PubMed]

32. Lin, H.; Lin, D.; Xiong, X.S. Roles of human papillomavirus infection and stathmin in the pathogenesis of sinonasal inverted papilloma. Head Neck 2016, 38, 220-224. [CrossRef]

33. Alvarez-Aldana, A.; Martínez, J.W.; Sepúlveda-Arias, J.C. Comparison of five protocols to extract DNA from paraffin-embedded tissues for the detection of human papillomavirus. Pathol. Res. Pract. 2015, 211, 150-155. [CrossRef] [PubMed]

34. Kocjan, B.J.; Hošnjak, L.; Poljak, M. Detection of alpha human papillomaviruses in archival formalin-fixed, paraffin-embedded (FFPE) tissue specimens. J. Clin. Virol. 2016, 76, S88-S97. [CrossRef]

35. Božić, L.; Jovanović, T.; Šmitran, A.; Janković, M.; Knežević, A. Comparison of HPV detection rate in formalin-fixed paraffinembedded tissues of head and neck carcinoma using two DNA extraction kits and three amplification methods. Eur. J. Oral. Sci. 2020, 128, 501-507. [CrossRef] [PubMed]

36. Wang, M.J.; Noel, J.E. Etiology of sinonasal inverted papilloma: A narrative review. World J. Otorhinolaryngol. Head Neck Surg. 2017, 3, 54-58. [CrossRef]

37. Scheel, A.; Lin, G.C.; McHugh, J.B.; Komarck, C.M.; Walline, H.M.; Prince, M.E.; Zacharek, M.A.; Carey, T.E. Human papillomavirus infection and biomarkers in sinonasal inverted papillomas: Clinical significance and molecular mechanisms. Int. Forum Allergy Rhinol. 2015, 5, 701-707. [CrossRef]

38. Stepp, W.H.; Farzal, Z.; Kimple, A.J.; Ebert, C.S., Jr.; Senior, B.A.; Zanation, A.M.; Thorp, B.D. HPV in the malignant transformation of sinonasal inverted papillomas: A meta-analysis. Int. Forum Allergy Rhinal. 2021, 11, 1461-1471. [CrossRef]

39. McCormick, J.P.; Suh, J.D.; Lee, J.T.; Wells, C.; Wang, M.B. Role of High-Risk HPV Detected by PCR in Malignant Sinonasal Inverted Papilloma: A Meta-Analysis. Laryngoscope 2021. [CrossRef]

40. Kim, J.Y.; Yoon, J.K.; Citardi, M.J.; Batra, P.S.; Roh, H.J. The prevalence of human papilloma virus infection in sinonasal inverted papilloma specimens classified by histological grade. Am. J. Rhinol. 2007, 21, 664-669. [CrossRef]

41. Nishino, K.; Sekine, M.; Kodama, S.; Sudo, N.; Aoki, Y.; Seki, N.; Tanaka, K. Cigarette smoking and glutathione S-transferase M1 polymorphism associated with risk for uterine cervical cancer. J. Obstet. Gynaecol. Res. 2008, 34, 994-1001. [PubMed] 
42. Goudakos, J.K.; Blioskas, S.; Nikolaou, A.; Vlachtsis, K.; Karkos, P.; Markou, K.D. Endoscopic Resection of Sinonasal Inverted Papilloma: Systematic Review and Meta-Analysis. Am. J. Rhinol. Allergy 2018, 32, 167-174. [CrossRef] [PubMed]

43. Stoddard, D.G., Jr.; Keeney, M.G.; Gao, G.; Smith, D.I.; García, J.J.; O’Brien, E.K. Transcriptional activity of HPV in inverted papilloma demonstrated by in situ hybridization for E6/E7 mRNA. Otolaryngol. Head Neck Surg. 2015, 152, 752-758. [CrossRef] [PubMed] 